\title{
PENGARUH BALL PEENING TERHADAP KEKERASAN BAJA TAHAN KARAT AISI 316L
}

\author{
Teguh Dwi Widodo'1, Rudianto Raharjo² \\ 1,2Jurusan Teknik Mesin Fakultas Teknik Universitas Brawijaya \\ JI. MT. Haryono 167 Malang 65145 \\ Telp/ Fax (0341) 8051752 \\ E-mail: widodoteguhdwi@ub.ac.id
}

\begin{abstract}
In this work, ball peening was performed in order to evaluate its effect on the AISI $316 \mathrm{~L}$ hardness. The process was conducted by employing AISI E52100 Chrome Steel ball which has hardness 752 HVN as bomber. In this research ball peening process was performed at three different nozzle pressure (6, 7, and 8 bar) for 5 minutes. Vickers Micro Hardness Tester and Digital Optical Microscope was used to characterize the samples hardness and grains structure respectively. The results showed that the hardness of AISI 316L was improved. It may due to plastic deformation which toke places on its grains.
\end{abstract}

\section{PENDAHULUAN}

AISI 316L stainless steel merupakan baja yang tahan terhadap korosi, jumlahnya berlimpah, relatif murah dan mudah untuk dibuat [1], [2] dan [3]. Penggunaannya terbentang dari perangkat sederhana seperti osteosynthesis plates [4] sampai yang lebih canggih seperti hip prosthesis [3]. Bentuk hip prostheses kompleks yang terdiri dari kepala femoral dan batang yang mengkopensasi beban bantalan, keausan dan ketahanan lelah [5].

Biomaterial seperti stainless steel $316 \mathrm{~L}$ adalah material yang dilindungi oleh lapisan oksida tipis yang bisa mencegah reaksi logam tersebut dengan lingkungannya. Lapisan yang biasa disebut lapisan passive tersebut mempunyai ikatan kimia dalam bentuk kromium oksida $\mathrm{Cr}_{2} \mathrm{O}_{3}$ oksida [6], [7], [8], [9] dan [10]. Meskipun ketebalan passive film biasanya hanya beberapa nanometer, tapi mereka bertindak sebagai penghalang yang sangat protektif antara permukaan logam dan lingkungan biologis yang agresif. Tingkat perlindungan dari passive film ditentukan oleh laju perpindahan ion dari film. Pengangkutan ion melalui film dipengaruhi oleh komposisi kimia dari passive film, struktur, ketebalan dan adanya cacat. Disisi lain, sejumlah penelitian telah melaporkan masalah fraktur kelelahan dan keausan permukaan kepala femoral [11], kekuatan mekanik dan stabilitas batang hip prostheses [12]. Permasalahan ini memiliki efek buruk pada pasien yang mengakibatkan penolakan implan oleh jaringan di sekitarnya [13]. Salah satu metode untuk menyelesaikan masalah tersebut yaitu dengan memodifikasi material pembuatnya. Sementara itu AISI 316L tidak dapat ditingkatkan sifat mekanisnya dengan perlakukan panas, terlebih modifikasi komposisi kimia material dapat mempengaruhi kompatibelitas material untuk digunakan menjadi bio material. Maka dari itu peningkatan sifat mekanisnya dilakukan dengan beberapa metode yang lain, salah satunya yaitu mechanical surface treatment, misalnya steel ball peening. Mekanisme metode ini yaitu meningkatkan sifat mekanik dengan memanfaatkan bola - bola baja untuk menimbulkan deformasi plastis pada permukaan substrat.

Tujuan dari penelitian ini mengungkap pengaruh steel ball peening terhadap kekerasan baja tahan karat AISI 316L. Beberapa penelitian mengunggkap bahwa kekerasan suatu material berpengaruh langsung terhadap sifat - sifat mekanis material seperti ketahanan aus, kekuatan tarik, serta ketahanan fatik.

\section{METODOLOGI PENELITIAN}

Pada penelitian ini material yang digunakan adalah Stainless steel AISI 316L dengan komposisi kimia dalam skala persen berat $(\% w t)$ terlihat pada Tabel 1. Baja tahan karat AISI 316L yang berupa lembaran dipotong dengan dimensi panjang $3 \mathrm{~mm}$, lebar 
$3 \mathrm{~mm}$ dan tebal $2 \mathrm{~mm}$ sebelum melewati tahap berikutnya untuk menjadi sampel penenitian.

Sebelum proses ball peening seluruh spesimen dipoles dengan menggunakan sand paper dari ukuran ISO 600 hingga ISO 1000. Selanjutnya dipoles menggunakan Autosol® untuk mendapatkan kekasaran permukaan yang lebih homogen serta menghilangkan pengotornya. Nilai kekasaran yang didapatkan setelah dihaluskan dan dipoles adalah antara $\mathrm{Ra}=0.55 \mu \mathrm{m}$ sampai $\mathrm{Ra}=0.57 \mu \mathrm{m}$. Setalah pemolesan, sampel dibersihakan menggunakan air yang kemudian dilanjutkan dengan pembilasan dengan menggunakan Etanol 98\%.

Proses ball peening menggunakan media AISI E52100 Chrome Steel ball sebagai ball bomber yang memiliki diameter $5 \mathrm{~mm}$ serta menggunakan kompresor dan gun blaster sebagai alatnya. Tekanan pada proses ball peening yaitu 6,7 , dan 8 bar dan jarak penembakan $3 \mathrm{~cm}$. Proses ball peening dilakukam selama 5 menit dengan sudut $90^{\circ}$. Diagaram proses ball peening di tunjukkan pada Gambar 1.

Tabel 1. Komposisi kimia Stainless steel AISI $316 \mathrm{~L}$

\begin{tabular}{ccccc}
\hline Karbon $(\mathrm{C})$ & Mangan $(\mathrm{Mn})$ & Fosfor $(\mathrm{P})$ & Sulfur $(\mathrm{S})$ & Silikon $(\mathrm{Si})$ \\
\hline 0,03 & 2,00 & 0,045 & 0,03 & 0,75 \\
\hline $\begin{array}{c}\text { Molybdenum } \\
(\mathrm{Mo})\end{array}$ & Nitrogen $(\mathrm{N})$ & Besi $(\mathrm{Fe})$ & Chromium $(\mathrm{Cr})$ & Nikel (Ni) \\
\hline 2,2 & 0,10 & 67.8 & 16,7 & 12,4 \\
\hline
\end{tabular}

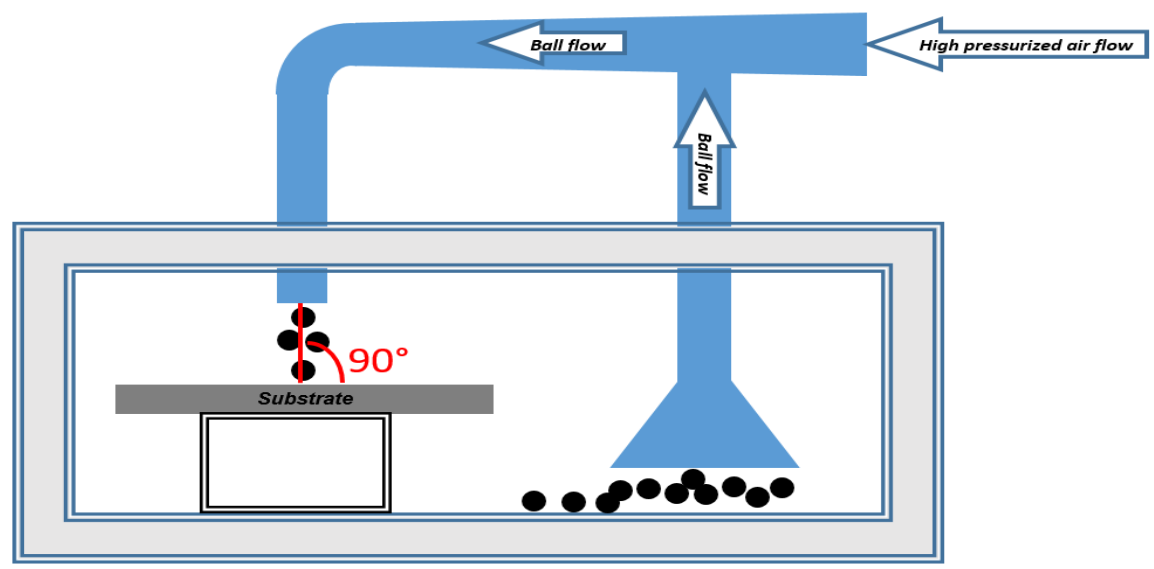

Gambar 1 Diagram proses ball peening

Untuk mengetahui nilai distribusi kekerasan pada AISI 316L akibat proses ball peening uji kekerasan dengan menggunakan alat uji Digital Micro Vickers Hardness Tester TH712® dilakukan pada penampang melintang (cross sesction) substrat yang terkena proses ball peening. Diagram pengambilan titik indentasi (indentation spot) untuk pengujian kekerasan tersebut ditunjukkan pada Gambar 2.
Indentation spot Cross section surface

Ball peened surface

Gambar 2 Diagram pengambilan titik kekerasan 
Jarak antara titik pengujian satu dengan yang lebih kecil. Pada ball peening dengan

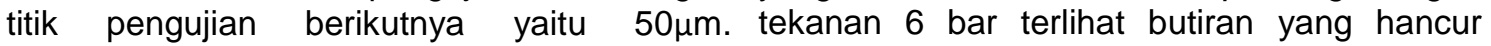
Sedangkan untuk mengetahui perubahan (crash) dan ada garis-garis deformasi. struktur mikro butir AISI 316L, observasi Sedangkan pada pada tekanan 8 bar menggunakan digital mikroskop optik dilakukan prosentasi butir yang hancur meningkat dan juga pada penampang melintang substrat. garis deformasi tidak terlihat lagi.

Sebelumnya, untuk dapat melihat butir, proses etsa berdasarkan ASTM E 407 dilakukan pada AISI 316L yang telah mengalami perlakuan ball peening ataupun yang tanpa perlakuan (raw materialnya).

\section{HASIL DAN PEMBAHASAN \\ Strukturmikro butir AISI 316L}

Gambar 3 menunjukkan struktur mikro AISI 316L baik sebelum proses ball peening. Sedangkan Gambar 4 menunjukkan struktur mikro AISI 316L setelah proses ball peening. Dari gambar tersebut dapat dilihat efek dari proses ball peening terhadap stuktur butir dari AISI 316L. Butir dari AISI 316L mengalami perbaikan setelah mengalami proses ball peening, hal ini dapat di lihat dari ukuran butir

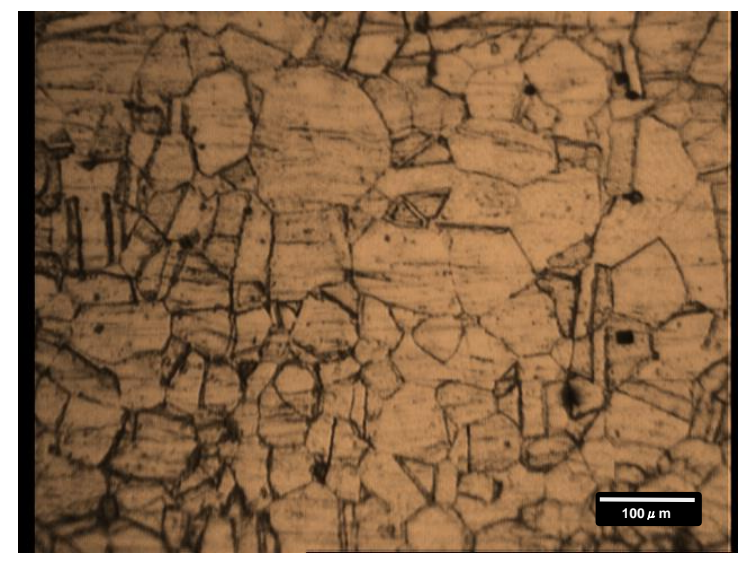

Gambar 3 Struktur mikro AISI 316L tanpa perlakuan
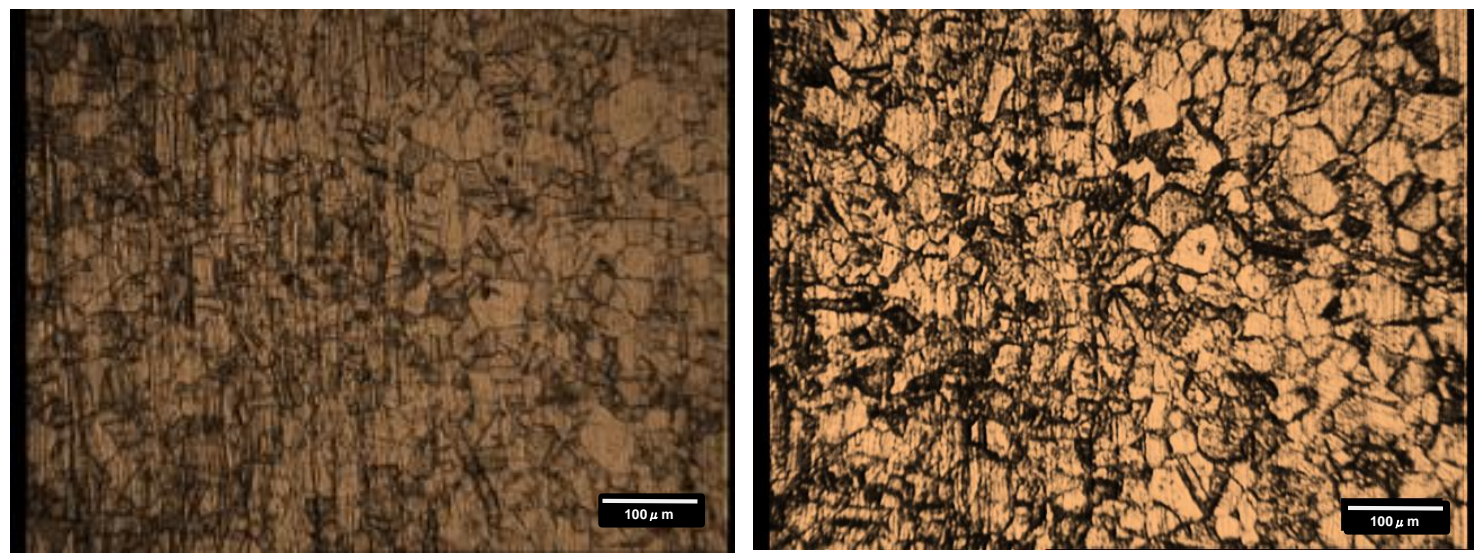

Gambar 4 Struktur mikro AISI 316L Setelah mengalami proses ball peenig dengan tekanan (a) 6 bar (b) 8 bar

Perbaikan ukuran butir ini diakibatkan ukurannya menjadi lebih halus. Perubahan pada proses ball peening terjadi deformasi ukuran butir ini sangat terlihat jelas terlihat pada plastis. Tegangan yang bekerja pada daerah yang dekat dengan permukaan yang permukaan baja tahan karat AISI 316L yang terkena proses ball peening.

diakibatkan oleh tumbukan bola baja melebihi tegangan luluh (yield strength) dari baja tahan karat AISI 316L sehingga deformasi plastis terjadi. Ketika tegangan ini trus diberikan dan melebihi tegangan maksimumnya (ultimate stergth) maka slip terjadi pada butir. Slip ini dapat dilihat dengan terjadinya butiran yang

\section{Kekerasan AISI $316 L$}

Setelah proses ball peening kekerasan dari baja tahan karat AISI 316L di uji. Hasil pengujian kekersan dari AISI $316 \mathrm{~L}$ yang telah mengalami proses ball peening ditunjukkan oelh Gambar 5. Dari hasil pengujian didapat 
peningkatan kekerasan maksimal terjadi pada materian yang mengalami proses ball peening dengan tekanan 8 bar. Kekerasan dari baja tahan karat AISI 316L meningkat menjadi 750,1 VHN dari kekerasan awal yang tanpa mengalami perlakuan yaitu sebesar 237 VHN pada pengujian kekerasan $50 \mu \mathrm{m}$ dari permukaan substrat. Kekerasan ini meningkat siknifikan yaitu sebesar $216,5 \%$. Peningkatan kekerasan ini dimungkinkan terjadi karena adanya perbaikan ukuran butir pada substrat yang disebabkan oleh proses deformasi plastis. Peningkatan kekerasan ini dimungkinkan terjadi karena adanya perbaikan ukuran butir pada substrat yang disebabkan oleh proses deformasi plastis Peningkatan kekerasan juga dialami pada proses ball peening dengan variasi tekanan 6 bar dan 7 bar, masing masing mengalami peningkatan menjadi 738,2
HVN dan 674,2 HVN pada pengujian $50 \mu m$ dari permukaan substrat. Peningkatan kekerasan ini lebih sedikit jika dibandingkan dengan AISI $316 \mathrm{~L}$ yang mengalami proses ball peening dengan tekanan 8 bar. Hal ini di mungkinkan karena adanya perbedaan tegangan yang bekerja pada substart. Semakin besar tekanan yang diberikan pada proses ball peening maka semakin bersar pula tegangan yang bekerja pada substrat sehingga daerah yang terdeformasi semakin luas, mendalam dan berkelanjutan. Hal ini dapat pada Gambar 4, bahwa semakin besar tekanan maka jarak daerah yang terdeformasi dari permukaan semakin besar pula. Selain itu ukuran butir juga semakin kecil. Disisi lain, semakin kecil ukuran butir maka kekeran semakin naik.

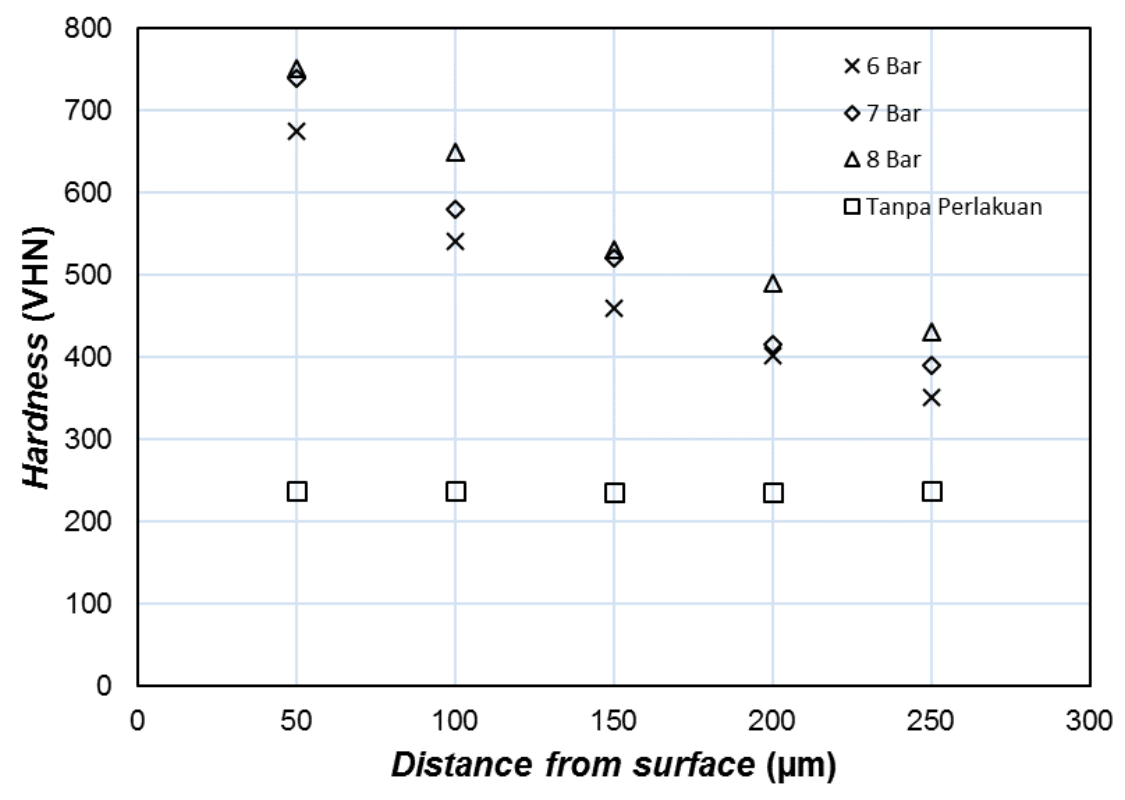

Gambar 5 Kekerasan AISI 316L setelah proses ball peening

\section{KESIMPULAN}

Berdasarkan hasil yang didapat dari penelitian ini maka dapat disimpulkan bahwa ball peening mampu meningkatkan kekerasan baja tahan karat AISI 316L. Peningkatan kekerasan ini diakibatkan oleh adanya perbaikan butir pada permukaan AISI 316L yang terkena proses ball peening. Dapat disimpulkan juga bahwa kekerasan baja tahan karat AISI $316 \mathrm{~L}$ meningkat seiring kenaikan tekanan nozle pada proses ball peening.

\section{DAFTAR PUSTAKA}

[1] M.D. Pereda, K.W. Kang, R. Bonetto, C. Llorente, P. Bilmes, C. Gervasi, 2012 Impact of surface treatment on the corrosion resistance of ASTM F138-F139 stainless steel for biomedical applications, 
Procedia Material Science. Vol. 1 pp. 446- [8] I. Milosev, M. Metikos-Hukovic, H.H. 453.

[2] H. Yang, K. Yang, B. Zhang, 2007, Pitting corrosion resistance of $\mathrm{La}$ added $316 \mathrm{~L}$ stainless steel in simulated body fluids, Material Letter. Vol. 61. pp. 1154.

Strehblow, 2000, Passive film on orthopaedic TiAIV alloy formed in physiological solution investigated by $X$ ray photoelectron spectroscopy, Biomaterial. Vol. 21. pp. 2103-2113.

[3] J. Walczak, F. Shahgaldi, F. Heatley, 1998, [9] I. Milosev, H.H. Strehblow, 2000, The In vivo corrosion of $316 \mathrm{~L}$ stainless steel hip implants: morphology and elemental compositions of corrosion products, Biomaterials. Vol. 19. Pp. 229-235.

[4] G.K. Triantafyllidis, A.V. Kazantzis, K.T. Karageorgiou, 2007, Premature fracture of a stainless steel $316 \mathrm{~L}$ orthopaedic plate implant by alternative episodes of fatigue and cleavage decoherence, Enggineering Failure Anallysis. Vol. 14. pp. 1346-1350.

[5] S. Griza, G. Zanon, E.P. Silva, F. Bertoni, A. Reguly, T.R. Strohaecker, 2009, Design aspects involved in a cemented THA stem failure case, Enggineering Failure Anallysis, Vol. 16. pp. 512

[6] J.W. Schultze, M.M. Lohrengel, 2000, Stability, reactivity and breakdown of passive films. Problems of recent and future research, Electrochimica Acta, Vol. 45 No. (15-16) pp. 2499-2513.

[7] P. Schmuki, 2002, From bacon to barriers: a review on the passivity of metals and alloys, J. Solid State Electrochemical. Vol. behavior of stainless steels in physiological solution containing complexing agent studied by $X$-ray photoelectron spectroscopy, Journal of Biomedical Material, Vol. 52. pp. 404-412.

[10] I. Milosev, H.H. Strehblow, 2003, The composition of the surface passive film formed on CoCrMo alloy in simulated physiological solution, Electrochimica Acta Vol. 48 pp. 2767-2774.

[11] S.H. Teoh, 2000, Fatigue of biomaterials: a review, International Journal of Fatigue, Vol. 22. pp. 825-837

[12] M. Jasty, W.J. Maloney, C.R. Bragdon, D.O. O'Connor, T. Haire, W.H. Harris, 1991, The initi-ation of failure in cemented femoral components of hip arthroplasties, Bone Joint Surg. Vol. 20 Ser. B. No. 73. pp. $551-557$

[13] D. F. Williams, 1976, Corrosion of implant materials, Annual Review Material. Sci. Vol. 6. pp. $237-245$. 